\title{
Different airway smooth muscle cells phenotypes are involved in intrinsic and extrinsic obstruction in guinea pig asthma model
}

\section{Mayra D Alvarez-Santos}

Universidad Nacional Autonoma de Mexico

\section{Álvarez-González Marisol}

Instituto Nacional de Enfermedades Respiratorias

\section{Eslava-De Jesus Elizabeth}

Instituto Nacional de Enfermedades Respiratorias

\section{Angel González-López}

Instituto Nacional de Enfermedades Respiratorias

\section{Pacheco-Alba Ivonne}

Instituto Nacional de Enfermedades Respiratorias

Pérez-Del Valle Yazmín

Instituto Nacional de Enfermedades Respiratorias

\section{Rojas-Madrid Rodrigo}

Instituto Nacional de Enfermedades Respiratorias

Blanca Bazan-Perkins ( $\sim$ perkins@unam.mx)

Instituto nacional de Enfermedades Respiratorias Ismael Cosio Villegas / Tecnológico de Monterrey https://orcid.org/0000-0003-1331-6349

\section{Research}

Keywords: Airway smooth muscle, airway obstruction, IL-13 TGF- $\beta 1$, GSH, SERCA, airway responsiveness, remodeling, phenotype

Posted Date: February 24th, 2020

DOI: https://doi.org/10.21203/rs.2.24340/v1

License: (c) (i) This work is licensed under a Creative Commons Attribution 4.0 International License.

Read Full License 


\section{Abstract}

Background: Airway obstruction in asthma is driven by airway smooth muscle (ASM) contraction. Airway obstruction can be induced extrinsically by direct stimulation of ASM with contractile agonists or by indirect provocation with antigens, while the airway baseline tone is dependent on intrinsic obstruction. The ASM phenotypes involved in all types of obstruction seem to be related.

Methods: To determination the associations of the ASM phenotypes involved in different types of airway obstruction, guinea pigs were sensitized to ovalbumin and repetitively challenged with antigen. At the third challenge, histamine provocation was used to evaluate airway responsiveness (AR), and lung samples were obtained to calculate the airway wall area. ASM cells from the trachea were disaggregated to determine 1) the percentage of cells that expressed transforming growth factor- $\beta 1$ (TGF- $\beta 1$ ), interleukin-13 (IL-13) and sarco-endoplasmic $\mathrm{Ca}^{2+}$ ATPase-2b (SERCA2b) by flow cytometry; 2 ) SERCA2B gene expression by RT-PCR; 3 ) the level of reduced glutathione (GSH) by ELISA; and 4) the sarcoplasmic reticulum $\mathrm{Ca}^{2+}$ refilling rate by microfluorometry. The control guinea pig group received only saline instead of ovalbumin. Comparisons were made using t-tests, and the associations were determined using Spearman correlation coefficient analysis.

Results: Antigenic challenges induced airway obstruction and progressive incremental changes in airway baseline tone. The AR to histamine and the expression of TGF- $\beta 1$ in ASM cells was increased in the asthma model. The airway wall mass and expression of IL-13 and SERCA2b in ASM cells were similar between groups. SERCA2B gene expression and GSH levels were reduced in the asthma group. The extent of antigen-induced airway obstruction was directly associated with ASM cell TGF- $\beta 1$ expression and the degree of AR. The magnitude of AR and antigen-induced airway obstruction showed an inverse correlation with GSH levels. The airway baseline tone showed an inverse association with SERCA2b expression. No relationship was observed between direct or indirect airway obstruction and the airway tone. After caffeine withdrawal, the rate of sarcoplasmic reticulum $\mathrm{Ca}^{2+}$ refilling was similar in both groups.

Conclusions: Each type of airway obstruction depends on different ASM phenotypes: 1) direct and indirect airway obstruction seems to be sensitive to the level of ASM oxidative stress; 2) indirect obstruction induced by antigen appears to be influenced by the expression of TGF- $\beta 1$ in ASM; and 3) the SERCA2b expression level in ASM cells plays a role in the intrinsic airway tone.

\section{Introduction}

Airway smooth muscle (ASM) is a central structure involved in the development of asthma physiopathology since it contributes to the development of airway hyperresponsiveness (AHR) and variable airflow obstruction. In addition, ASMs have a persistent contractile force capable of maintaining a high airway intrinsic baseline tone, which is increased in asthma patients $[1,2]$. Notably, it has been 
suggested that the airway basal tone is an underlying contributor to the airway contractile capacity and AHR through tonic activation of ASM $[3,4,5]$.

It has been recognized that ASM is not only a primary contributor to the development of physiological alterations in asthma but also induces important airway environmental changes [6]. For example, sensitization of ASM with IgE upregulated the expression of interleukin-13 (IL-13) in isolated rabbit trachea via a process that enhances the contractility of ASM due to autocrine effects [7]. In small isolated airways from humans, IL-13 can induce AHR [8], and IL-13 can increase both the baseline airway tone and the airway responsiveness in murine lung slices [5]. Another example is transforming growth factor $\beta 1$ (TGF- $\beta 1$ ), a cytokine that is produced at high levels by ASM cells in asthma. TGF- $\beta 1$ is a potent profibrogenic factor involved in multiple cellular responses, such as differentiation, proliferation and survival [9]. Although the effects of TGF- $\beta 1$ on airway contractility are controversial, it is recognized that this cytokine can be involved in airway remodelling by inducing ASM proliferation and fibrosis and increasing airway wall mass $[9,10]$. It has been revealed that changes in airway basal tone can also be attributed to airway wall enlargement induced by structural changes [11].

Another factor that can induce changes in airway physiology is oxidative stress. Reduced glutathione (GSH) is a thiol antioxidant that is highly expressed in the epithelial lining fluid and within airway cells, where it acts as a regulator of the cell cycle and enzyme substrates. When it becomes oxidized, GSH forms glutathione disulfide (GSSG), which can inhibit the antioxidant capabilities of the airways through depletion of the total GSH pool [12]. Such an interaction promotes histone acetylation by increasing histone acetyltransferase activity and inhibiting histone deacetylase activity in airway cells, leading to the enhanced release of proinflammatory cytokines [13]. In addition, GSH relaxes the trachea and suppresses AHR to histamine by activating ASM potassium channels [14]. GSH reduces the airway tone, unlike oxidative molecules, which have been shown to be related to increased airway tone and AHR [15].

ASM contraction occurs through an increase in intracellular calcium $\left(\mathrm{Ca}^{2+}\right)$ levels. The baseline $\mathrm{Ca}^{2+}$ levels in ASM are maintained by the constant removal of $\mathrm{Ca}^{2+}$ either by pumps present on the plasma membrane or by the sarco-endoplasmic reticulum $\mathrm{Ca}^{2+}$ ATPase (SERCA). Of the three isoforms, SERCA2b is found in smooth muscles. Indeed, in ASM cells from asthma patients, AHR has shown to be related to downregulation of the function and expression of SERCA2b [16]. Until now, the role of SERCA2b in airway baseline tone has been unknown.

Guinea pigs have been a valuable tool in the study of human asthma. Direct stimulation of ASM with agonists such as histamine or indirect provocation with antigens in guinea pigs produce robust airway obstruction because guinea pigs have a large ASM mass [17]. In addition to the extrinsic responses induced by direct and indirect provocation, the guinea pig asthma model has shown an increase in intrinsic baseline tone [18].

It has been found that individual smooth muscle cells can develop changes in their phenotype after phvsiolocical and batholoaical stimulation [19]. In canine trachea, two populations of myocyte subsets Loading [MathJax]/jax/output/CommonHTML/fonts/TeX/fontdata.js 
have been observed that show differences in contractile phenotype protein abundances and proliferative capacities [20].

Our aim was to identify the phenotype of ASM cells that is related to intrinsic and extrinsic airway obstruction and the relationship between the different types of airway obstruction in an asthma model in guinea pigs.

\section{Materials And Methods}

\section{Study design}

As described in Fig. 1, after the initial sensitization, guinea pigs were intermittently exposed to aerosolized ovalbumin via up to three antigenic challenges. At the last challenge, the development of antigen-induced airway responsiveness was evaluated by generating dose-response curves showing the response to histamine before and after an antigenic challenge. Afterward, the animals were sacrificed to obtain lung and trachea samples. In the lung samples, areas in the lamina propria and the ASM layer were analysed through light microscopy. ASM cells were disaggregated from the trachea, and flow cytometry was used to determine the percentages of cells that expressed TGF- $\beta 1$, IL-13 and SERCA2b. SERCA2B gene expression was determined in isolated ASM cells by RT-PCR. The level of GSH in ASM cells was measured by ELISA. Statistical analysis of the association of each parameter in ASM cells with values related to extrinsic and intrinsic airway obstruction was performed using Spearman correlation coefficient analysis. Some ASM cells were loaded with Fura-2 acetoxymethyl ester (Fura-2/AM), and the sarcoplasmic reticulum $\mathrm{Ca}^{2+}$ refilling rate after caffeine withdrawal was evaluated by microfluorometry. Control animals received sham treatment with saline solution.

\section{Animals}

The experiments were performed with healthy male guinea pigs with weights of 350-400 g that were originally purchased from Harlan Mexico (strain HsdPoc:DH) and bred in our institutional laboratory animal facilities. The guinea pigs were bred in a filtered, air-conditioned environment at $21 \pm 1^{\circ} \mathrm{C}$ with 50 $70 \%$ humidity and 12/12-h light/dark cycles, fed sterilised pellets (2040 Harlan Teklad Guinea-Pig Diet; USA) and allowed access to water ad libitum.

\section{Asthma model}

Guinea pigs were sensitized and challenged with ovalbumin (asthma model) or saline (control) solutions according to previously described methods [17] (Fig. 1). Antigen or saline nebulization was performed in acrylic chambers, and pulmonary function was recorded by using a whole-body single-chamber plethysmograph for freely moving animals (Buxco Electronics Inc., Troy, NY, USA). The signal from the chamber was processed with the included software (Buxco Bio System XA v1.1) to calculate several respiratory parameters, including the broncho-obstructive index $(\mathrm{Bi})$. This index was determined using the 


$$
\mathrm{Bi}=((\mathrm{Te}-\mathrm{Rt}) / \mathrm{Rt})(\mathrm{PEP} / \mathrm{PIP})
$$

where $\mathrm{Te}=$ expiratory time $(\mathrm{s}), \mathrm{Rt}=$ relaxation time $(\mathrm{s}), \mathrm{PEP}=$ peak expiratory pressure $\left(\mathrm{cmH}_{2} \mathrm{O}\right)$, and $\mathrm{PIP}=$ peak inspiratory pressure $\left(\mathrm{cmH}_{2} \mathrm{O}\right)$.

The software was adjusted to include only breaths with a tidal volume of $1 \mathrm{ml}$ or more in the analysis, with a minimal inspiratory time of $0.15 \mathrm{~s}$, a maximal inspiratory time of $3 \mathrm{~s}$, and a maximal difference between the inspiratory and expiratory volumes of $10 \%$. After the guinea pig was placed inside the plethysmographic chamber, a 5 min baseline Bi recording was initiated 10 min later. Starting one minute after aerosol administration, the Bi was recorded at 5 and $10 \mathrm{~min}$ and then every 15 min thereafter. Because the Bi was calculated for each breath, adjustments were made in the software to determine the average values for all breaths occurring over a $15 \mathrm{~s}$ interval and then to average these values during the last 5 min of each period.

Aerosols containing ovalbumin or saline were produced by a US-1 Bennett nebulizer (flow, 2 ml/min; Multistage liquid impinger, Burkard Manufacturing Co., Rickmansworth, Hertfordshire, UK), which released a mixture of particles with sizes of $<4 \mu \mathrm{m}(44 \%), 4-10 \mu \mathrm{m}(38 \%)$, and $>10 \mu \mathrm{m}(18 \%)$.

Airway responsiveness was evaluated at the third antigenic challenge by the administration of noncumulative doses of histamine $(0.001$ to $0.1 \mathrm{mg} / \mathrm{ml})$ aerosol before and after antigen or saline exposure. The histamine doses were delivered over $1 \mathrm{~min}$, and the Bi over the following 10 min was determined. The interval between histamine doses was $10 \mathrm{~min}$. The dose-response curve was complete when the Bi reached three times its baseline level. The second histamine curve was determined three hours after the antigen or saline challenge.

\section{Isolation of tracheal smooth muscle cells}

One hour after completing the second histamine curve, guinea pigs were subjected to an overdose of an intraperitoneal injection of pentobarbital sodium $(65 \mathrm{mg} / \mathrm{kg})$, and the trachea and left lung lobe were obtained. Airway smooth muscle that was free of epithelium and connective tissue was dissected and incubated for $10 \mathrm{~min}$ at $37^{\circ} \mathrm{C}$ in $5 \mathrm{ml}$ of Hanks' solution (Gibco, Grand Island, NY, USA) containing $2 \mathrm{mg}$ of cysteine and $0.05 \mathrm{U} / \mathrm{ml}$ papain. The tissue was washed in Leibovitz's solution and placed in physiological saline solution containing (mM): $25 \mathrm{NaHCO}_{3}, 118 \mathrm{NaCl}, 1.2 \mathrm{KH}_{2} \mathrm{PO}_{4}, 4.6 \mathrm{KCl}, 1.2 \mathrm{MgSO}_{4}$, and 11 glucose. The smooth muscle was cut into small strips $(5 \times 0.5 \mathrm{~mm})$ weighing $200 \mathrm{mg}$ total and placed in $2.5 \mathrm{ml}$ physiological saline solution containing collagenase type I $(1 \mathrm{mg} / \mathrm{ml}$; Boehringer-Mannheim, Indianapolis, IN, USA) and dispase II (4 mg/ml) for $10 \mathrm{~min}$ at $37^{\circ} \mathrm{C}$. This procedure was repeated twice. Leibovitz's solution was added to stop the enzymatic activity, and the tissue was dispersed mechanically until isolated cells were observed.

\section{Flow cytometry}


Isolated smooth muscle cells were incubated with $10 \mathrm{~g} / \mathrm{ml}$ brefeldin-A for $4 \mathrm{~h}$ at $37^{\circ} \mathrm{C}$ to inhibit cytokine release. Then, the cells were fixed with $4 \% \mathrm{p}$-formaldehyde for $10 \mathrm{~min}$ at $4^{\circ} \mathrm{C}$, washed, and permeabilized with $0.1 \%$ saponin, $10 \% \mathrm{BSA}$ and $1 \% \mathrm{NaN}_{3}$ in PBS. The cells then underwent gentle shaking in the dark for $15 \mathrm{~min}$ at room temperature and were labelled with surface marker antibodies ( $1 \mu \mathrm{l} / 1 \times 10^{6}$ cells $)$ against SERCA2b (clone 2A7-A1, mouse monoclonal SERCA2b ATPase, Abcam, Cambridge, MA, USA), IL-13 (human monoclonal, labeled with APC; BD Biosciences, San Diego, CA, USA) and TGF-b1 (clone 9016, labeled with phycoerythrin; R\&D Systems, Minneapolis, MN, USA). Another incubation was performed with the secondary antibody conjugated to FITC (BD Biosciences Pharmingen, San Diego, CA, USA) for 30 min. Then, the cells were analysed for marker expression with a FACScan flow cytometer (Becton Dickinson, San Jose, CA, USA) using CellQuest software, and 10,000 events were counted. To analyse the staining, the blasts were first gated according to their physical properties (forward and side scatter). Next, a second gate was drawn based on the fluorescence characteristics of the gated cells, and the fluorescence intensity was assessed with histograms. The intensity of the fluorescence staining is expressed as the mean fluorescence intensity. Control staining was performed using fluorochromeconjugated isotype-matched antibodies. Background staining contributed to $<1 \%$ of the total signal and was subtracted from the experimental values.

\section{Real-time quantitative polymerase chain reaction}

Total RNA was extracted from tracheal smooth muscle strips obtained from guinea pigs using TRIzol reagent (Life Technologies, Grand Island, NY, USA). The RNA quality was assessed by resolving the fragments on denatured $1 \%$ agarose gels and measurement of the absorbance ratios at 260/280 nm. Total RNA (1 mg) was reverse-transcribed using Moloney murine leukaemia virus reverse transcriptase and $2 \mu \mathrm{g}$ of random primers according to the manufacturer's protocol (Advantage RT-for-PCR Kit; Clontech, Palo Alto, CA, USA). Quantitative real-time PCR amplification was performed using the iCycler iQ Detection System (Bio-Rad, Hercules, CA, USA). PCR was performed with the CDNA working mixture in a $20 \mu \mathrm{l}$ reaction volume containing $20 \mathrm{mM}$ Tris- $\mathrm{HCl}, 2 \mu \mathrm{l}$ of cDNA, $200 \mu \mathrm{M}$ dNTP, $2 \mathrm{mM} \mathrm{MgCl}_{2}, 50 \mathrm{mM} \mathrm{KCl}$, $1 \mu \mathrm{M}$ each of the specific $5^{\prime}$ and 3' primers, $1.25 \mathrm{U}$ of Taq DNA polymerase (Roche, Branchburg, NJ, USA) SYBR green $(1: 50,000)$ and $10 \mathrm{nM}$ fluorescein (Roche, Indianapolis, IN, USA) at pH 8.3. The primer pair used for SERCA2b amplification was designed in Primer BLAST. The sequences were 5'TTAAAGCAACTGTCTATTTCTGCTG-3' and 5'- AGTCAGAAAAAGCAAAACAAAATCTA-3' (Merck KGaA, Darmstadt, Germany). The PCR cycling conditions consisted of $95^{\circ} \mathrm{C}$ for $10 \mathrm{~min}$ followed by 40 cycles of $95^{\circ} \mathrm{C}$ for $15 \mathrm{~s}$ and $60^{\circ} \mathrm{C}$ for $1 \mathrm{~min}$. The $18 \mathrm{~S}$ gene was used as an endogenous gene to normalize the RNA expression (Applied Biosystems ${ }^{\circledR}$ Eukaryotic $18 \mathrm{~S}$ rRNA Endogenous Control (FAM ${ }^{\mathrm{Tm}}$ MGB Probe, NonPrimer Limited), Thermo Fisher Scientific, USA). After 40 cycles, the delta-Ct method was used to compare the levels of the transcripts. The results were calculated as 2 elevated to the negative power of the difference between the CT value of each gene minus the CT value of 18S (2-Dct).

\section{Measurement of intracellular $\mathrm{Ca}^{2+}$}


Myocytes were loaded with $3 \mu \mathrm{M}$ Fura-2/AM in physiological saline solution for $1 \mathrm{~h}$ at $25^{\circ} \mathrm{C}$. Then, the cells were allowed to settle into a perfusion chamber mounted on a Nikon inverted microscope (Diaphot 200; Minato-ku, Tokyo, Japan). The cells that adhered to the glass were continuously perfused at a rate of $2.5 \mathrm{ml} / \mathrm{min}$ with physiological saline solution $\left(37^{\circ} \mathrm{C}\right.$, equilibrated with $95 \% \mathrm{O}_{2}$ and $5 \% \mathrm{CO}_{2}, \mathrm{pH} 7.4$ ) containing $2 \mathrm{mM} \mathrm{Ca}^{2+}$. Cells were excited by alternating pulses of 340-and 380-nm-wavelength light, and the light emitted at $510 \mathrm{~nm}$ was measured using a PTI microphotometer (Photon Technology International, Princeton, NJ, USA). The cells in the field were removed before beginning the experiments. The background fluorescence was automatically subtracted by removing cells from the field. The fluorescence acquisition rate was $0.5 \mathrm{~s}$. The intracellular $\mathrm{Ca}^{2+}$ concentration was calculated according to the Grynkiewicz et al. [21] formula. The Kd of Fura-2 was assumed to be 386 nM [22]. The mean 340/380 fluorescence ratios corresponding to Rmax and Rmin were determined by exposing the cells to $10 \mathrm{mM}$ $\mathrm{Ca}^{2+}$ in the presence of $10 \mu \mathrm{M}$ ionomycin and to $\mathrm{Ca}^{2+}$-free phosphate saline solution with $1.11 \mathrm{mM}$ ethylene glycol-bis(ß-aminoethyl ether)-N,N,N, $N$-tetraacetic acid (EGTA), respectively. Rmax was 11.7, and Rmin was 0.5 . The fluorescence ratio resulting from $380 \mathrm{~nm}$ light excitation in $\mathrm{Ca}^{2+}$-free solution and $\mathrm{Ca}^{2+}$-saturated cells (ß) was 7.5.

\section{Reduced glutathione (GSH) measurement}

Isolated myocytes were rapidly homogenized, and $100 \mathrm{mg}$ of pelleted cells were mixed with $300 \mu \mathrm{L}$ of $5 \%$ saline solution. The samples were centrifuged at $12,000 \mathrm{xg}$ at $4^{\circ} \mathrm{C}$ for $20 \mathrm{~min}$. The supernatant was collected, and quantitative measurement of GSH in the supernatant was performed with the GSH assay kit (ab235670, Abcam, USA). This kit utilizes a specific enzymatic cycling method in the presence of GSH and a fluorophore. The reduction of the fluorophore produces a stable fluorescent product, the fluorescence of which is directly proportional to the amount of GSH in the sample and can be tracked kinetically $(E x / E m=535 / 587 \mathrm{~nm})$.

\section{Automated morphometry analysis in lung tissues}

The left lung lobe was fixed by manually perfusing it with $10 \%$ neutral buffered formaldehyde solution. The lung fragments were cut and embedded in paraffin, and $4 \mu \mathrm{m}$-thick lung sections were stained with Masson trichrome stain. The areas containing lamina propria and smooth muscle $\left(\mu \mathrm{m}^{2}\right)$ were determined through the use of automated morphometry (Qwin, Leica Microsystems Imaging Solutions, Cambridge, UK). All measurements were conducted in six bronchi and six bronchioles chosen at random from each animal. The data were adjusted according to the length of the corresponding basement membrane, and their average value was considered the final result. Bronchi and bronchioles were identified by the presence or absence of cartilage in the airway wall, respectively.

\section{Drugs and reagents}

Ovalbumin (chicken egg albumin grade II), Fura-2/AM, brefeldin-A, caffeine, cyclopiazonic acid, EGTA, ionomvcin. Dabain. dispase Il. cvsteine. histamine dihvdrochloride, and all salts and stains used for Loading [MathJax]/jax/output/CommonHTML/fonts/TeX/fontdata.js 
microscopy were purchased from Sigma Chemical Co. (St. Louis, MO, USA). Aluminium hydroxide was purchased from J.T. Baker (Phillipsburg, NJ, USA). Pentobarbital sodium was acquired from Pfizer (Toluca, Mexico). Fura-2/AM and CPA were dissolved in dimethyl sulfoxide (final concentration 0.025\%). In the control experiments, dimethyl sulfoxide had no effect.

\section{Statistical analysis}

The Dbaseline Bi represented the difference between the reinforcement value and the last baseline $\mathrm{Bi}$ value obtained before challenge. Airway responsiveness to histamine was evaluated according to the provocative dose $200 \%\left(\mathrm{PD}_{200}\right)$, i.e., the interpolated histamine dose that caused a three-fold increase in comparison to the basal $\mathrm{Bi}$. Changes in histamine responsiveness induced by saline or antigenic challenges were evaluated by means of a paired Student's $t$-test and by dividing the $\mathrm{PD}_{200}$ observed after challenge by the $\mathrm{PD}_{200}$ value observed before challenge ( $\mathrm{PD}_{200}$ ratio). For multiple group comparisons, repeated measures ANOVA followed by Dunnett's tests was used. Associations between TGF- $\beta 1$, GSH or SERCA-2b and changes in lung function were assessed through Spearman correlation coefficient analysis. Statistical significance was indicated by a two-tailed $P<0.05$. The data in the text and figures are expressed as the mean \pm SEM.

\section{Results}

\section{Antigen-induced lung functional changes}

After sensitization and reinforcement with antigen, ovalbumin challenge induced transient airway obstruction. The average maximal obstructive response (Rmax) observed during the first through the third antigen challenge was higher in the guinea pig asthma model than in the control group $(P<0.01 ; n=6$ and 9 for the control and asthma model groups, respectively; Fig. 2A). Airway responsiveness was evaluated by comparing histamine responses before and after the last challenge. The $\mathrm{PD}_{200}$ ratio in the control group was close to 1 , meaning that the $\mathrm{PD}_{200}$ value after saline challenge was similar to the initial challenge $\mathrm{PD}_{200}$ value. In the asthma model, the $\mathrm{PD}_{200}$ after antigen challenge was lower than the $\mathrm{PD}_{200}$ obtained before challenge, and the $\mathrm{PD}_{200}$ ratio was significantly lower than that obtained in the control group ( $P<0.05 ; n=6$ and 9 for the control and asthma model groups, respectively; Fig. 2B). The changes in the airway baseline $\mathrm{Bi}$ (intrinsic tone) determined before direct or indirect airway provocation are shown in Fig. $2 \mathrm{C}$. During the challenges, the change compared to the airway baseline $\mathrm{Bi}$ (Dbaseline $\mathrm{Bi}$ ) in the asthma model was increased in comparison that in the controls $(P<0.05 ; n=6$ and 9 for the control and asthma model groups, respectively; Fig. $2 \mathrm{D})$. The $\mathrm{PD}_{200}$ ratio showed an inverse association with airway obstruction ( $r=-0.5, P=0.04$ ), meaning that an increased AHR resulted in an increased Rmax. No correlation was observed between the extent of antigen-induced obstruction and the $\mathrm{PD}_{200}$ ratio according to Dbaseline $\mathrm{Bi}(r=0.14, P=0.3$, and $r=0.18, P=0.25$, respectively).

\section{Relationship of GSH levels in myocytes with functional changes}


The levels of GSH were decreased in asthma model guinea pigs in comparison with those in controls $(P=$ $0.0064, n=6$; Fig. 3A). The GSH levels showed a direct correlation with the $\mathrm{PD}_{200}$ ratio $(P=0.003, n=13$;

Fig. 3B) and an inverse correlation with $\operatorname{Rmax}(P=0.00001, n=15$; Fig. 3C), implying that the greater the GSH level was, the lower the levels of antigen-induced AHR and airway obstruction were. The GSH levels were not correlated with Dbaseline $\mathrm{Bi}(r=0.04, P=0.48, n=12)$.

\section{Relationship of IL-13 and TGF- $\beta 1$ expression in myocytes with airway functional and structural changes}

In isolated tracheal myocytes, the number of myocytes that expressed IL-13 did not change between groups (Fig. 4A). The number of cells that expressed TGF- $\beta 1$ was increased in the asthma model compared with that in the control group ( $P<0.05 ; n=6$ each group; Fig. 4B). GSH levels were inversely correlated with the expression of TGF- $\beta 1$ in myocytes $(P=0.03, n=12$; Fig. $4 \mathrm{C})$. No correlation was observed between the number of cells that expressed TGF- $\beta 1$ and the $\mathrm{PD}_{200}$ ratio or Dbaseline Bi (TGF- $\beta 1$ vs $\mathrm{PD}_{200}$ ratio and Dbaseline $\mathrm{Bi}: r=-0.42, P=0.07$, and $r=0.13, P=0.32$, respectively), but a positive correlation was observed between the number of cells that expressed TGF- $\beta 1$ and Rmax $(P<0.025, n=$ 12; Fig. 4D). The number of cells that expressed IL-13 was not correlated with the $\mathrm{PD}_{200}$ ratio, Dbaseline Bi or Rmax.

The increase in the number of myocytes that expressed TGF- $\beta 1$ did not affect the mass of the airway wall, indicating that the increase in TGF- $\beta 1$ was not able to produce fibrosis or changes in the airway smooth muscle mass ( $n=6$ each, bronchi and bronchioles; Fig. 5). No correlation was observed between the mass of the airway wall and TGF- $\beta 1$ levels or changes in lung function according to Dbaseline Bi, the $\mathrm{PD}_{200}$ ratio or Rmax.

\section{Relationship of SERCA2b expression in myocytes with functional changes}

The number of ASM cells that expressed SERCA2b did not change between groups; nevertheless, the RTPCR results showed a decrease in SERCA2B gene expression in tracheal smooth muscle in the asthma model group in comparison with that in controls $(P=0.00001, n=6$ each group; Fig. 6A-B). The number of myocytes that expressed SERCA2b showed a direct correlation with the number of myocytes that expressed IL-13 ( $P=0.02, n=9$; Fig. $6 \mathrm{C})$. An inverse relationship was observed between Dbaseline Bi and the number of myocytes that expressed SERCA2b $(P=0.001, n=11$; Fig. 6D). No significant correlation was observed between the number of myocytes that expressed SERCA2b and the $\mathrm{PD}_{200}$ ratio, Rmax, or TGF- $\beta 1$ and GSH levels.

To evaluate the rate of re-uptake of $\mathrm{Ca}^{2+}$ by SERCA, the $\mathrm{Ca}^{2+}$ in the sarcoplasmic reticulum in myocytes was depleted by incubating the cells with $10 \mathrm{mM}$ caffeine for $2 \mathrm{~min}$. The refilling of the sarcoplasmic reticulum was allowed to produce a $\mathrm{Ca}^{2+}$ undershoot after caffeine withdrawal (Fig. 7). In the control and asthma model myocytes, the basal $\mathrm{Ca}^{2+}$ levels were comparable $(137 \pm 7.6 \mathrm{nM}, n=6 ; 139 \pm 6.8 \mathrm{nM}, n=$ 5). The rate of $\mathrm{Ca}^{2+}$ decrease during $\mathrm{Ca}^{2+}$ undershoot in myocytes from control and asthma model guinea 
pigs was similar ( $4.6 \pm 0.6 \mathrm{nM} / \mathrm{s}, n=6$ and $4.3 \pm 0.5 \mathrm{nM} / \mathrm{s}, n=5$, respectively; Fig. 7), suggesting that the reuptake of $\mathrm{Ca}^{2+}$ by SERCA was not altered in the asthma model.

\section{Discussion}

Asthma is a heterogeneous disorder characterized by pathophysiological alterations of airways that are responsible for the symptoms of the disease. In this study, we observed that the guinea pigs that showed a greater response to direct ASM stimulation with histamine and, consequently, a high AHR also presented greater airway obstruction in response to indirect challenge with antigen, suggesting that the behaviour of ASM in the asthma model reflected a hypercontractile phenotype. It was previously shown that an increase in ASM contractile capacity induced an increase in airway tone and enhanced airway responsiveness [3]. Our results showed that the change in the baseline intrinsic tone did not show any association with the extent of airway obstruction induced by either direct or indirect provocation. Indeed, our results suggest that in the guinea pig asthma model, the mechanism involved in the change in the baseline intrinsic tone was different from that that induced hypercontractility. Therefore, the hypercontractile phenotype of ASM was associated with decreased levels of GSH, highlighting the importance of redox balance to ASM cell behaviour.

Glutathione is considered the principal cellular redox buffer molecule. In a healthy cell, $98 \%$ of glutathione is found in its reduced form, GSH. Lung GSH depletion has been observed in an allergic asthma model in guinea pigs [14]. This depletion could play an important role in anaphylaxis. In mast cells, GSH is capable of abating histamine release [23], while in isolated tracheal rings, GSH reduced the contraction induced by histamine compared with that induced by carbachol or 5-hydroxytryptamine [24]. It is known that the response to antigen provocation in guinea pigs is mainly induced by the release of histamine [25]. Therefore, the increase in the direct or indirect histamine response observed in our study can be explained by the reduction of GSH in ASM cells. In addition, the reduction of GSH could be produced by TGF- $\beta 1$ because it is known that TGF- $\beta 1$ has effects on redox balance by depleting glutathione levels [26].

TGF- $\beta 1$ is a pleiotropic cytokine with immunosuppressive, pro- and anti-inflammatory and fibrogenic properties [27]. Due to the role of this cytokine in fibroblast recruitment and proliferation, extracellular matrix synthesis and inhibition of matrix metalloproteinases, TGF- $\beta 1$ is considered to play a key role in airway remodelling and consequent airway narrowing [28]. In our study, although the percentage of ASM cells that expressed TGF- $\beta 1$ was increased in asthma model guinea pigs, we did not observe evidence of structural remodelling, such as changes in ASM mass or the development of subepithelial fibrosis. In addition, TGF- $\beta 1$ can contribute to bronchoconstriction by increasing the expression of contractile proteins [29] and enhancing force generation, agonist-induced contraction and excitation-contraction coupling by ASM [30]. This can explain the relationship between antigen-induced airway obstruction and TGF- $\beta 1$ levels observed in our study; paradoxically, airway responsiveness and TGF- $\beta 1$ levels were not associated, suggesting that there are some mechanisms involved in indirect challenge with antigen that are affected by TGF- $\beta 1$ that are not involved in the direct stimulation of ASM by histamine. In agreement 
$[30,31]$. In addition, TGF- $\beta 1$ is capable of directing immune responses against antigens, inducing allergic responses [32]. Thus, the main physiopathological role of TGF- $\beta 1$ in ASM cells seems to be the intensification of allergic responses to antigens.

An intracellular $\mathrm{Ca}^{2+}$ increase is necessary for ASM contraction. A key regulator of intracellular $\mathrm{Ca}^{2+}$ homeostasis in ASM is SERCA2b. The role of SERCA in ASM is dual: it causes muscle relaxation by lowering cytosolic $\mathrm{Ca}^{2+}$ levels and re-establishes the sarcoplasmic reticulum $\mathrm{Ca}^{2+}$ supply, which is necessary for muscle contraction; therefore, alterations in SERCA have been implicated in many types of pathological processes. It has been reported that the SERCA2b protein is specifically expressed in both native and cultured ASMs obtained from endobronchial biopsies of patients with asthma. SERCA activity can be influenced by various molecules, such as GSH. A steady supply of GSH results in Sglutathionylation of SERCA, increasing its activity [33]. In the heart, the increase in the expression of SERCA1a, the main SERCA isotype in cardiomyocytes, enhances myocyte contractility in response to caffeine in a gene-dose-dependent manner and alters myocyte shortening due to increased SERCA activity and $\mathrm{Ca}^{2+}$ buffering [34]. In contrast, decreasing SERCA levels in vascular smooth muscle will produce intracellular $\mathrm{Ca}^{2+}$ oscillations [35]. Human ASM cells from asthma patients did not show changes in baseline intracellular $\mathrm{Ca}^{2+}$ levels or the expression of SERCA; nevertheless, asthma patients with ASM cells with a increased rate of intracellular $\mathrm{Ca}^{2+}$ clearance were shown to have decreased lung function [36]. Another study showed that SERCA expression is diminished in ASM from asthma patients in comparison with that in ASM from healthy subjects and that the extent of this effect was correlated with the severity of disease [16]. In line with this finding, we observed in our study that the levels of the $S E R C A 2 B$ gene were reduced in ASM from the asthma group; however, SERCA2b protein expression did not show changes between groups. Furthermore, we found that the intrinsic baseline tone had an inverse association with the percentage of myocytes that expressed SERCA2b, suggesting that the increase in tone could be produced by reduced buffering of $\mathrm{Ca}^{2+}$; nevertheless, the sarcoplasmic reticulum $\mathrm{Ca}^{2+}$ refilling rate was similar in myocytes from controls and asthma model guinea pigs, suggesting that the function of SERCA2b was not altered in asthma model guinea pigs and that subtle changes in SERCA2b expression are enough to induce changes in the intrinsic baseline tone.

$\mathrm{IL}-13$ is a cytokine that has been related to the expression of SERCA and $\mathrm{Ca}^{2+}$ signalling. In murine ASM cells, IL-13 can induce $\mathrm{Ca}^{2+}$ signalling and contraction [37], while in human ASM cells, IL-13 can enhance $\mathrm{Ca}^{2+}$ responses after stimulation with histamine [38] and boost the contractility of airways via its autocrine effects on ASM [7]. In 2009, Sathish and coworkers [39] found that incubation of human ASM cells with IL-13 reduced the expression of SERCA2b, but in our study, we did not observe changes in the percentage of ASM cells that expressed IL-13 in the asthma model or the relationship of IL-13 expression with pathophysiological changes, although an association between IL-13 and SERCA2b in ASM cells was observed.

\section{Conclusions}


Taken together, the experimental results described in this study suggest that ASM cells are phenotypically heterogeneous and that some phenotypes are associated with different effects during airway obstruction. Because of this, the asthma model revealed a hypercontractile ASM phenotype characterized by low GSH levels. This hypercontractile phenotype is important in the development of extrinsic obstruction that produces either direct or indirect ASM provocation. Interestingly, an ASM cell phenotype that produces high levels of TGF- $\beta 1$ is predominantly characterised by extrinsic indirect obstruction induced by allergens. Finally, the intrinsic airway baseline tone is influenced by SERCA2b expression in ASM cells but not airway wall enlargement. The study of ASM cell phenotypes might be valuable for understanding the heterogeneity, variability and complexity of asthma.

\section{List Of Abbreviations}

Airway smooth muscle (ASM), airway hyperresponsiveness (AHR), interleukin-13 (IL-13), transforming growth factor $\beta 1$ (TGF- $\beta 1$ ), reduced glutathione (GSH), glutathione disulfide (GSSG), calcium $\left(\mathrm{Ca}^{2+}\right)$, sarco-endoplasmic reticulum $\mathrm{Ca}^{2+}$ ATPase (SERCA), broncho-obstructive index (Bi), Fura-2 acetoxymethyl ester (Fura-2/AM), ethylene glycol-bis(ß-aminoethyl ether)-N,N,N, $\mathrm{N}$-tetraacetic acid (EGTA), provocative dose $200 \%\left(\mathrm{PD}_{200}\right)$, maximal obstructive response (Rmax), the change compared to the airway baseline $\mathrm{Bi}$ (Dbaseline Bi)

\section{Declarations}

\section{Ethics approval:}

The protocol was revised and approved by the Scientific and Bioethics Committees of the Instituto Nacional de Enfermedades Respiratorias in Mexico City and in accordance with the Guide for the Care and Use of Laboratory Animals of the NIH (Guide for the Care and Use of Laboratory Animals, 1996).

\section{Consent to participate:}

Not applicable

\section{Consent for publication:}

Not applicable

\section{Availability of data and materials:}

The datasets used and/or analysed during the current study are available from the corresponding author on reasonable request.

\section{Competing interests:}




\section{Funding:}

This work was supported by SEP-CONACYT Ciencia Básica (256197).

\section{Authors' contributions:}

BPB contributed to the conception and design. ASM, AGM, EDJE, AGL, PAI, PDVY and RMR contributed to acquisition and interpretation of data and drafted the articleAl authors read and approved the final manuscript.

\section{Acknowledgements}

Not applicable

\section{References}

1. An SS, Bai TR, Bates JH, Black JL, Brown RH, Brusasco V, et al. Airway smooth muscle dynamics: a common pathway of airway obstruction in asthma. Eur Respir J. 2007;29(5):834-60.

2. Ellis JL, Undem BJ. Role of cysteinyl-leukotrienes and histamine in mediating intrinsic tone in isolated human bronchi. Am J Respir Critic Care Med. 1994;149(1)118-122.

3. Lee-Gosselin A, Gendron D, Blanchet MR, Marsolais D, Bossé Y. The gain of smooth muscle's contractile capacity induced by tone on in vivo airway responsiveness in mice. J Appl Physiol. 2015;118(6):692-8.

4. Molfino NA, Slutsky AS, Julia-Serda G, Hoffstein V, Szalai JP, Chapman KR, et al. Assessment of airway tone in asthma. Comparison between double lung transplant patients and healthy subjects. Am Rev Respir Dis. 1993;148:1238-43.

5. Bergner A, Kellner J, da Silva AK, Fischer R, Gamarra F, Huber RM. Bronchial hyperreactivity is correlated with increased baseline airway tone. Eur J Med Res. 2006;11(2):77.

6. Guida G, Riccio AM. Immune induction of airway remodeling. In Seminars Immunology. Academic Press; 2019. p. 101346.

7. Grunstein MM, Hakonarson H, Leiter J, Chen M, Whelan R, Grunstein JS, Chuang S. IL-13-dependent autocrine signaling mediates altered responsiveness of IgE-sensitized airway smooth muscle. Am J Physiol Lung Cell Mol Physiol. 2002;282(3):L520-8.

8. Manson ML, Säfholm J, James A, Johnsson AK, Bergman P, Al-Ameri M, et al. IL-13 and IL-4, but not IL-5 nor IL-17A, induce hyperresponsiveness in isolated human small airways. J Allergy Clin Immunol. 2019; doi: 10.1016/j.jaci.2019.10.037.

9. Makinde T, Murphy RF, Agrawal DK. The regulatory role of TGF-beta in airway remodeling in asthma. Immunol Cell Biol. 2007;85(5):348-56.

10. Chen G, Khalil N. TGF- $\beta 1$ increases proliferation of airway smooth muscle cells by phosphorylation of man kinases Resnir Res $2006 \cdot 7(1) \cdot$ ? 
11. Wang L, McParland BE, Pare PD. The functional consequences of structural changes in the airways: Implications for airway hyperresponsiveness in asthma. Chest, 2003;123 Suppl 3:356S-62S.

12. Kloek J, Mortaz E, van Ark I, Lilly CM, Nijkamp FP, Folkerts G. Glutathione prevents the early asthmatic reaction and airway hyperresponsiveness in guinea pigs. J Physiol Pharmacol. 2010;61(1):67-72.

13. Rahman I. Oxidative stress, transcription factors and chromatin remodelling in lung inflammation. Biochem Pharmacol. 2002 Sep 1;64(5-6):935-42.

14. Kloek J, Van Ark I, Bloksma N, De Clerck F, Nijkamp FP, Folkerts G. Glutathione and other lowmolecular-weight thiols relax guinea pig trachea ex vivo: interactions with nitric oxide?. Am J Physiol Lung Cell Mol Physiol. 2002;283(2):L403-8.

15. Cortijo J, Martí-Cabrera M, García J, de la AsunciónFederico VP, Esteras A, Bruseghini L, et al. Contraction of human airways by oxidative stress: Protection by n-acetylcysteine. Free Radical Biol Med.1999;27(3-4):392-400.

16. Mahn K, Hirst SJ, Ying S, Holt MR, Lavender P, Ojo OO, et al. Diminished sarco/endoplasmic reticulum $\mathrm{Ca}^{2+}$ ATPase (SERCA) expression contributes to airway remodelling in bronchial asthma. Proc Natl Acad Sci USA. 2009;106(26):10775-80.

17. Bazán-Perkins, B., Sánchez-Guerrero, E., Vargas, M.H., Martínez-Cordero, E., Ramos-Ramírez, P., Álvarez-Santos, et al. 2009. $\beta 1$-integrins shedding in a guinea-pig model of chronic asthma with remodelled airways. Clin Exp Allergy. 2009;39(5):740:51.

18. Bazán-Perkins B, Campos MG, Sánchez-Guerrero E. Polymerized type I collagen reverts airway hyperresponsiveness and fibrosis in a guinea pig asthma model. Inflammatory diseasesimmunopathology, clinical and pharmacological bases. InTech; 2012. p. 319-2.

19. Hirota JA, Nguyen TT, Schaafsma D, Sharma P, Tran T. Airway smooth muscle in asthma: phenotype plasticity and function. Pulm Pharmacol Ther. 2009;22(5):370-8.

20. Halayko AJ, Stelmack GL, Yamasaki A, McNeill K, Unruh H, Rector E. Distribution of phenotypically disparate myocyte subpopulations in airway smooth muscle. Can J Physiol Pharmacol. 2005;83(1):104-16.

21. Grynkiewicz G, Poenie $\mathrm{M}$, Tsien RY. A new generation of $\mathrm{Ca}^{2+}$ indicators with greatly improved fluorescence properties. J Biol Chem. 1985;260(6):3440-50.

22. Kajita JU, Yamaguchi HI. Calcium mobilization by muscarinic cholinergic stimulation in bovine single airway smooth muscle. Am J Physiol Lung Cell Mol Physiol. 1993;264(5):L496-503.

23. Di Bello MG, Masini E, loannides C, Ndisang JF, Raspanti S, Sacchi TB, Mannaioni PF. Histamine release from rat mast cells induced by the metabolic activation of drugs of abuse into free radicals. Inflamm Res.1998;47(3):122-30.

24. Assem ES, Mann S, Wan BY, Marson CM. Effect of antioxidants on airway smooth muscle contraction: action of lipoic acid and some of its novel derivatives on guinea pig tracheal smooth muscle. Inflamm Res. 2010;59 Suppl 2:S235-7. 
25. Ramos-Ramírez P, Campos MG, Martínez-Cordero E, Bazán-Perkins B, García-Zepeda E. Antigeninduced airway hyperresponsiveness in absence of broncho-obstruction in sensitized guinea pigs. Exp Lung Res. 2013;39(3):136-45.

26. Arsalane K, Dubois CM, Muanza T, Bégin R, Boudreau F, Asselin C, Cantin AM. Transforming growth factor- $\beta 1$ is a potent inhibitor of glutathione synthesis in the lung epithelial cell line A549: transcriptional effect on the GSH rate-limiting enzyme $\gamma$-glutamylcysteine synthetase. Am J Respir Cell Mol Biol.1997;17(5):599-607.

27. Bosse $Y$, Rola-Pleszczynski M. Controversy surrounding the increased expression of TGF beta 1 in asthma. Respir Res. 2007;8:66.

28. Fehrenbach $\mathrm{H}$, Wagner $\mathrm{C}$, Wegmann M. Airway remodeling in asthma: what really matters. Cell Tissue Res. 2017;367(3), 551-69.

29. Gawaziuk JP, Ma X, Sheikh F, Cheng ZQ, Cattini PA, Stephens NL. Transforming growth factor- $\beta$ as a differentiating factor for cultured smooth muscle cells. Eur Respir J. 2007;30(4):643-52.

30. Ojiaku CA, Cao G, Zhu W, Yoo EJ, Shumyatcher M, Himes BE, An SS, Panettieri Jr RA. TGF- $\beta 1$ evokes human airway smooth muscle cell shortening and hyperresponsiveness via Smad3. Am J Respir Cell Mol Biol. 2018;58(5):575-84.

31. Gordon ED, Sidhu SS, Wang ZE, Woodruff PG, Yuan S, Solon MC, et al. A protective role for periostin and TGF- $\beta$ in IgE-mediated allergy and airway hyperresponsiveness. Clin Exper Allergy, 2012;42(1):144-155.

32. Frischmeyer-Guerrerio PA, Guerrerio AL, Oswald G, Chichester K, Myers L, Halushka MK, Oliva-Hemker $\mathrm{M}$, Wood RA, Dietz HC. TGF $\beta$ receptor mutations impose a strong predisposition for human allergic disease. Sci Transl Med. 2013;5(195):195ra94.

33. Thompson MD, Mei Y, Weisbrod RM, Silver M, Shukla PC, Bolotina VM, et al. Glutathione adducts on sarcoplasmic/endoplasmic reticulum $\mathrm{Ca}^{2+}$ ATPase Cys-674 regulate endothelial cell calcium stores and angiogenic function as well as promote ischemic blood flow recovery. J Biol Chem. 2014;289(29):19907-16.

34. Teucher N, Prestle J, Seidler T, Currie S, Elliott EB, Reynolds DF, et al. Excessive sarcoplasmic/endoplasmic reticulum $\mathrm{Ca}^{2+}$-ATPase expression causes increased sarcoplasmic reticulum $\mathrm{Ca}^{2+}$ uptake but decreases myocyte shortening. Circulation. 2004;110(23):3553-9.

35. Johny JP, Plank MJ, David T. Importance of altered levels of SERCA, IP ${ }_{3} R$, and RyR in vascular smooth muscle cell. Biophys J. 2017;112(2):265-287.

36. Sweeney D, Hollins F, Gomez E, Mistry R, Saunders R, Challiss RA, Brightling CE. No evidence for altered intracellular calcium-handling in airway smooth muscle cells from human subjects with asthma. BMC Pulm Med. 2015;15:12.

37. Eum SY, Maghni K, Tolloczko B, Eidelman DH, Martin JG. IL-13 may mediate allergen-induced hyperresponsiveness independently of IL-5 or eotaxin by effects on airway smooth muscle. Am J Physiol Lung Cell Mol Physiol. 2005;288(3):L576-84. 
38. Risse PA, Jo T, Suarez F, Hirota N, Tolloczko B, Ferraro P, et al. Interleukin-13 inhibits proliferation and enhances contractility of human airway smooth muscle cells without change in contractile phenotype. Am J Physiol Lung Cell Mol Physiol. 2011;300(6):L958-66.

39. Sathish V, Thompson MA, Bailey JP, Pabelick CM, Prakash YS, Sieck GC. Effect of proinflammatory cytokines on regulation of sarcoplasmic reticulum $\mathrm{Ca}^{2+}$ reuptake in human airway smooth muscle. Am J Physiol Lung Cell Mol Physiol. 2009;297(1):L26-

\section{Figures}




\section{Control}

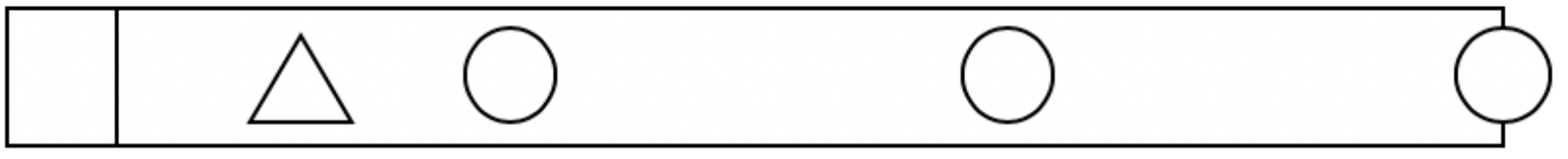

\section{Asthma model}
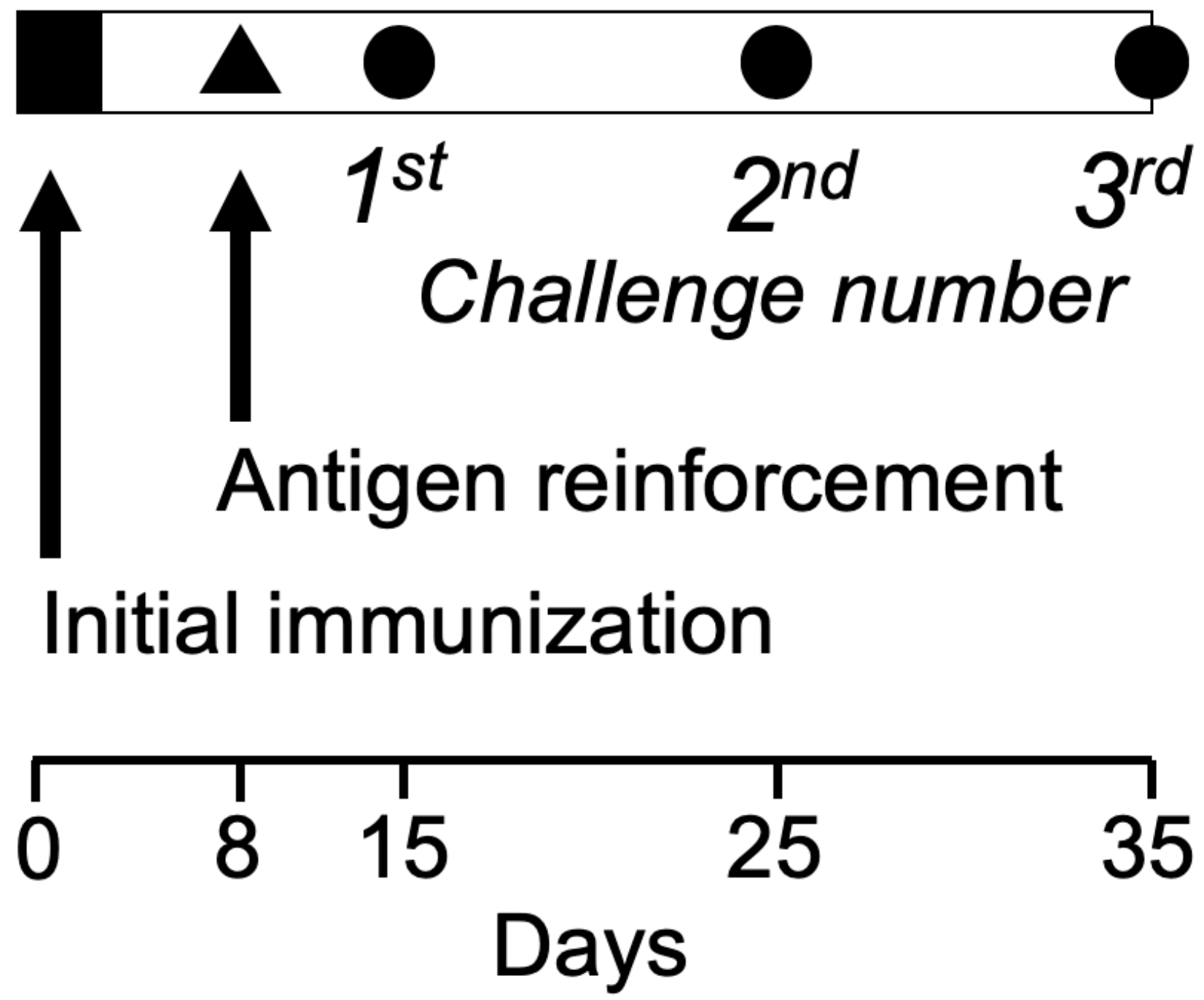

Figure 1

Experimental design. Guinea pigs were sensitized by intraperitoneal $(0.5 \mathrm{mg} / \mathrm{ml})$ and subdermal $(0.5$ $\mathrm{mg} / \mathrm{ml})$ injections with a combination of ovalbumin $(60 \mathrm{gg} / \mathrm{ml})$ and $1 \mathrm{mg} / \mathrm{ml}$ aluminium hydroxide dispersed in physiological saline solution (black squares). Eight days later, the sensitization was reinforced with ovalbumin aerosol administration for $5 \mathrm{~min}(3 \mathrm{mg} / \mathrm{ml}$; black triangle). From day 15 Loading [MathJax]/jax/output/CommonHTML/fonts/TeX/fontdata.js ovalbumin aerosol every 10 days; $1 \mathrm{mg} / \mathrm{ml}$ was 
used for the first challenge, and $0.5 \mathrm{mg} / \mathrm{ml}$ was used for the subsequent challenges (black circles). At the third challenge, dose-response curves in response to histamine were generated, and tissue acquisition was performed. The animals in the control group (open figures) received physiological saline solution instead of ovalbumin.
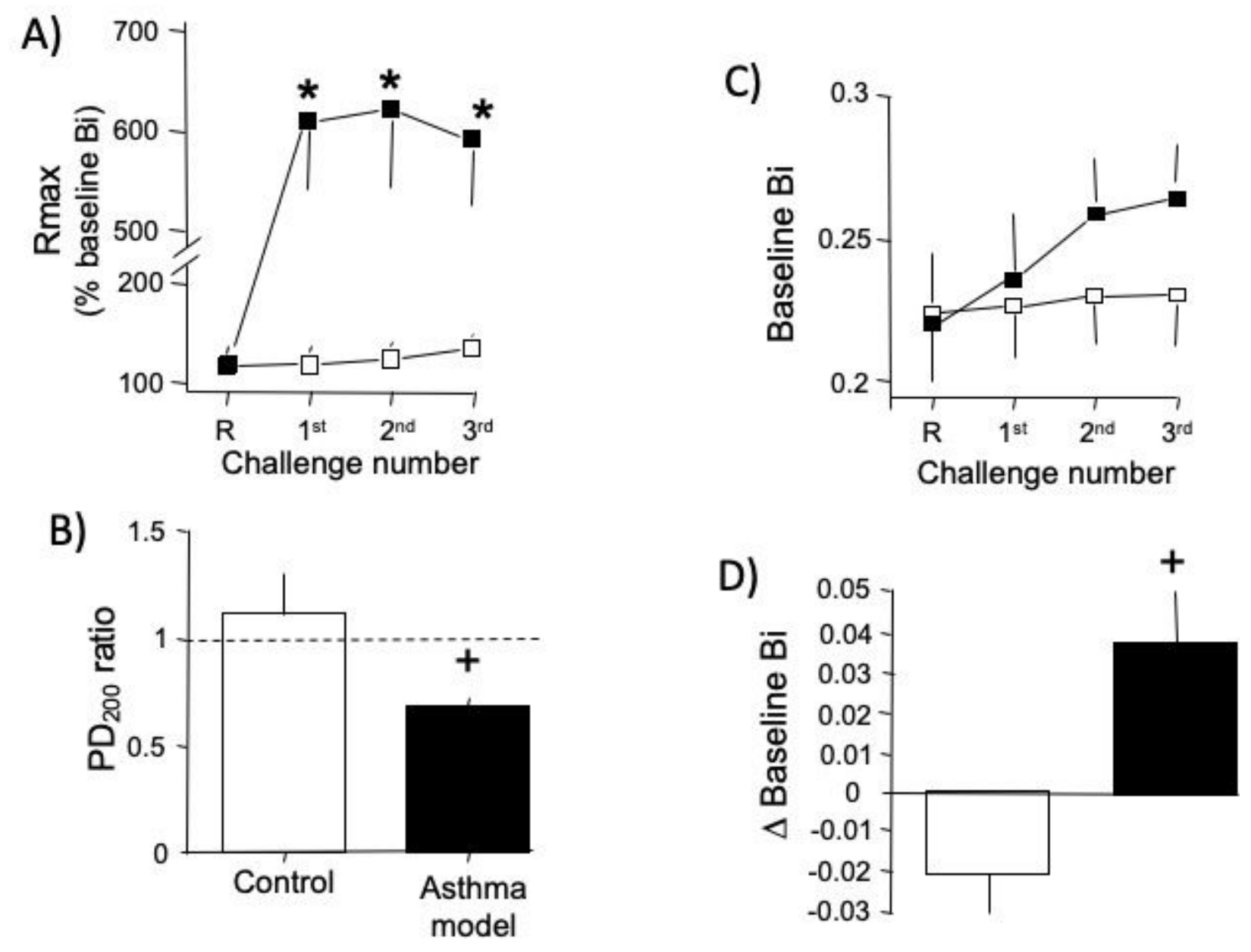

Figure 2

Antigen-induced changes in lung function in guinea pigs. (A) Average maximum (Rmax) bronchoobstructive index $(\mathrm{Bi})$ induced by indirect (ovalbumin antigen) provocation. (B) The PD200 ratio resulting from direct (histamine) provocation was determined according to the PD200 value observed after antigen challenge divided by the PD200 value determined before challenge. (C) The average intrinsic baseline Bi obtained before indirect and direct provocation. (D) Difference in the baseline $\mathrm{Bi}$ ( $\square$ baseline $\mathrm{Bi}$ ) obtained after reinforcement $(R)$ and the last challenge with saline (white bar, control) or antigen (black bar, asthma model). Values correspond to challenge with saline (white square) and antigen (black squares) in guinea pigs. ${ }^{*} \mathrm{P}<0.05$ compared with the control according to repeated measures ANOVA followed by Dunnett's test. $+P<0.05$ compared with the control (unpaired Student's t-test). The dotted line in B shows the border between hypo- and hyperresponsiveness. 

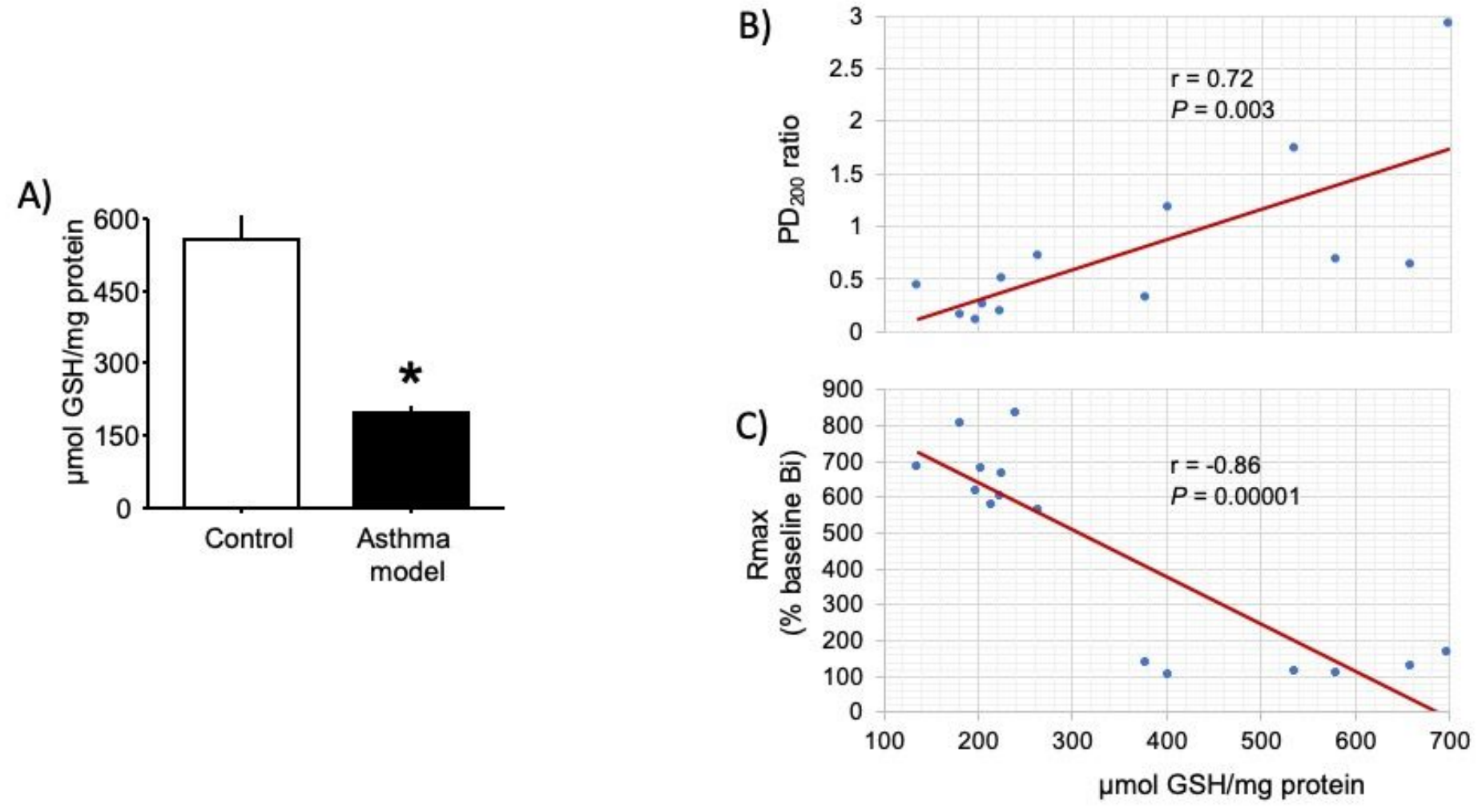

Figure 3

GSH changes in isolated airway smooth muscle cells from a guinea pig asthma model. (A) Levels of GSH in isolated myocytes. Scatter graphs showing that GSH levels were correlated (B) directly with changes in the PD200 ratio and (D) inversely with Rmax values. ${ }^{*} \mathrm{P}=0.0064$ compared with the control (unpaired Student's t-test). $r$ = Spearman correlation coefficient; $P$ = paired Student's t-test. 
A)

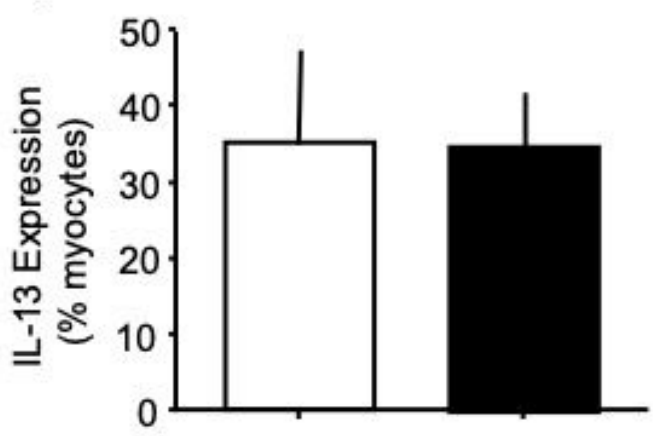

B)

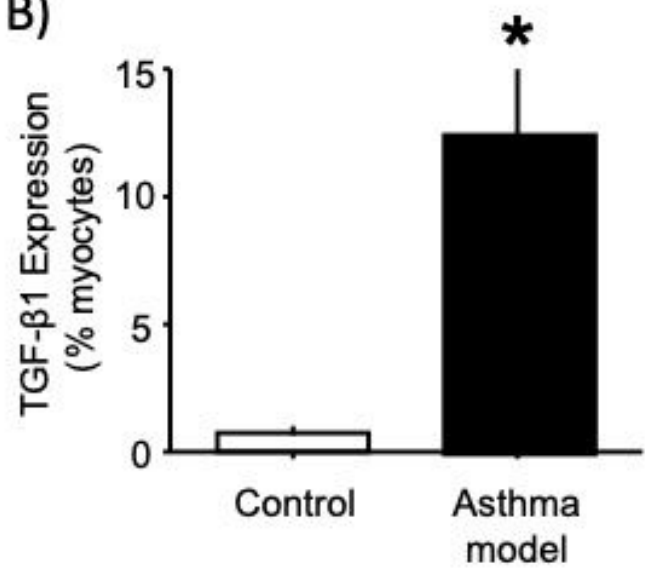

C)

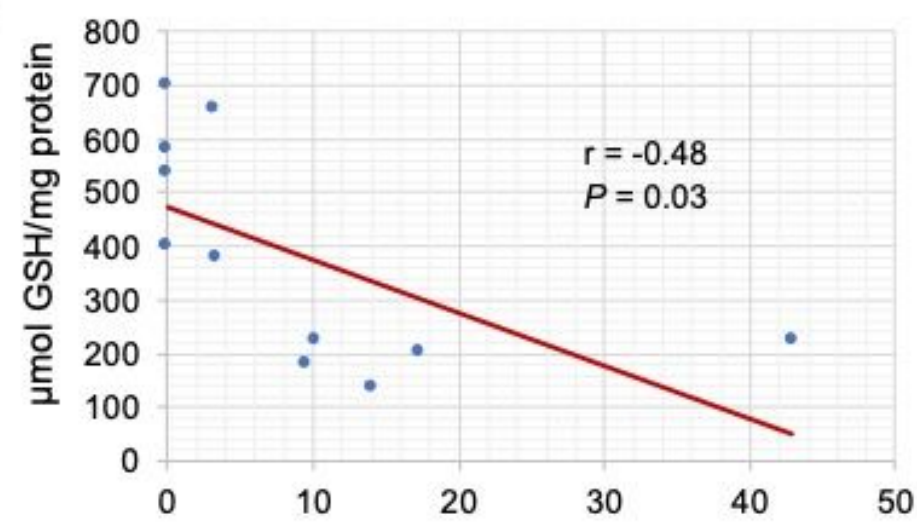

D) 1000

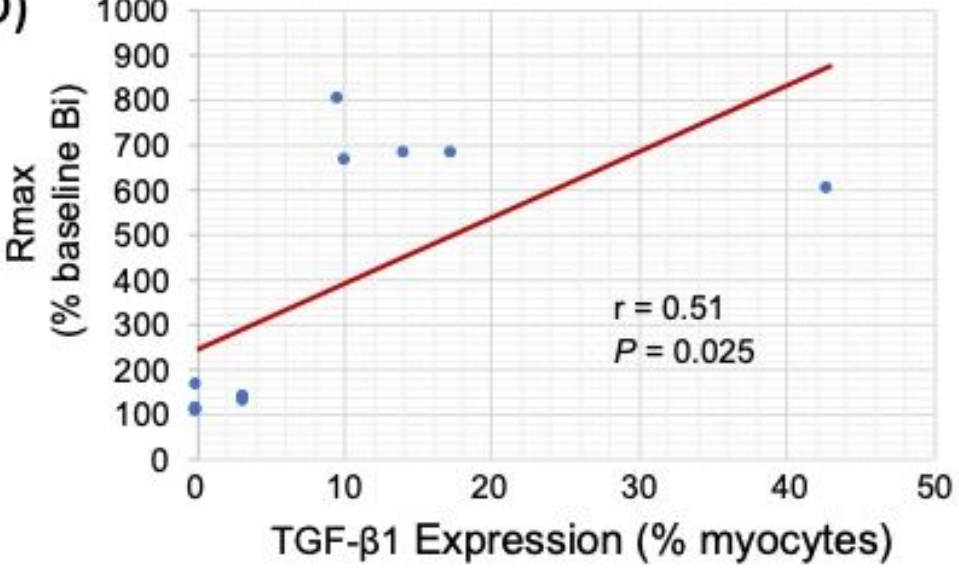

\section{Figure 4}

Number of isolated airway myocytes that expressed IL-13 and TGF- $\beta 1$ measured by flow cytometry. (A-B) Bars represent the mean + SEM. (C) Scatter graphs showing that the number of isolated airway myocytes that expressed TGF- $\beta 1$ was correlated inversely with GSH levels in myocytes and (D) directly with Rmax. ${ }^{*} \mathrm{P}<0.05$ compared with the control (unpaired Student's $\mathrm{t}$-test). $\mathrm{r}=$ Spearman correlation coefficient; $\mathrm{P}=$ paired Student's t-test. 
A) Lamina propia

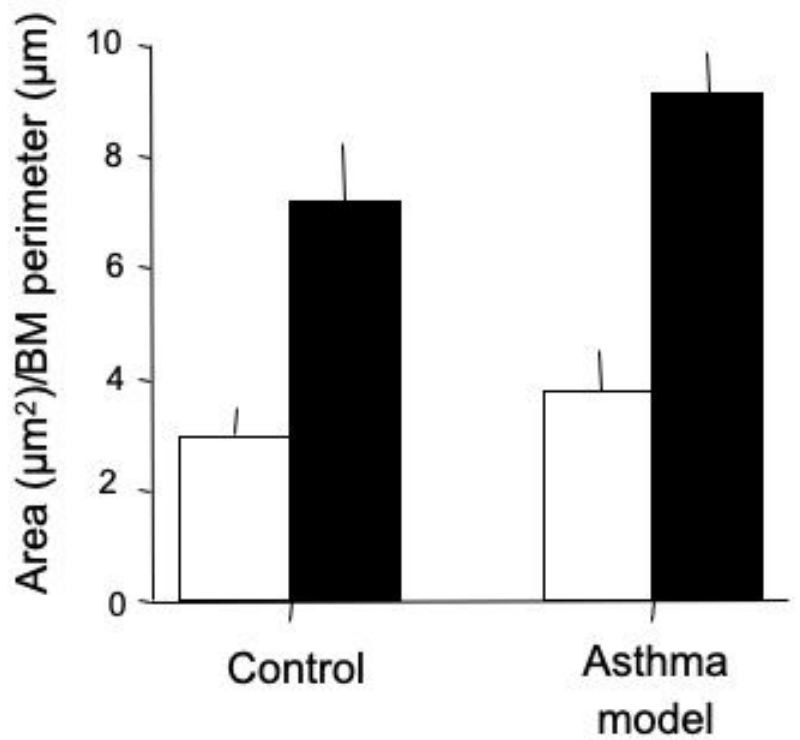

B)

\section{Airway smooth muscle}

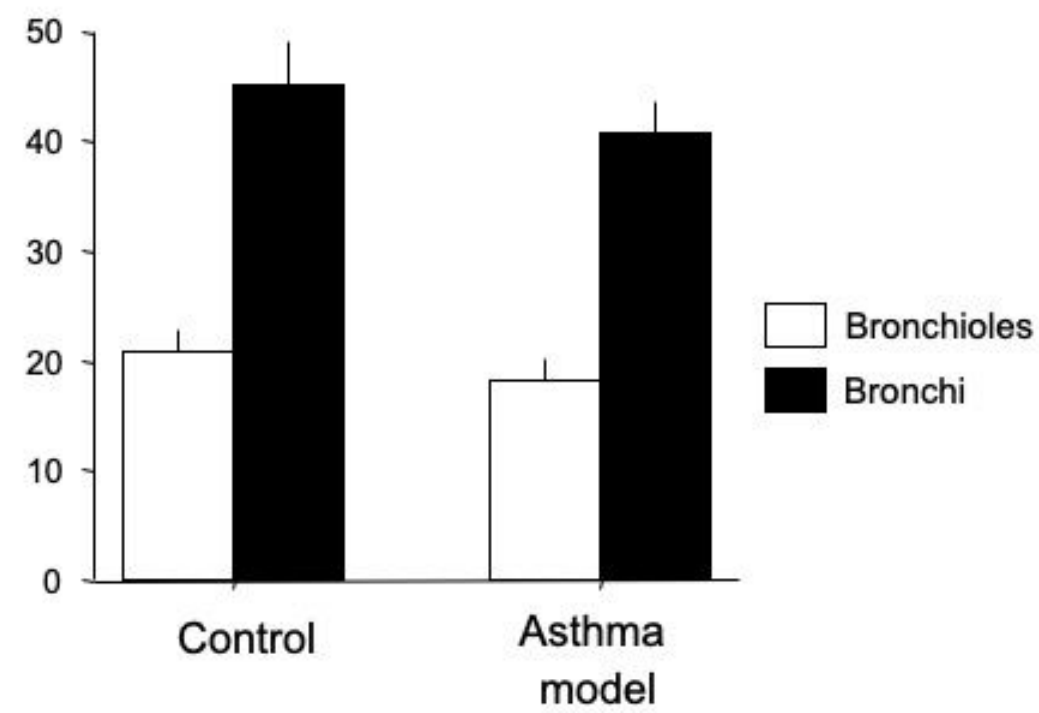

\section{Figure 5}

Airway wall areas. Data were adjusted according to the length of the corresponding basement membrane (BM). Bars represent the mean \pm SEM.

A)

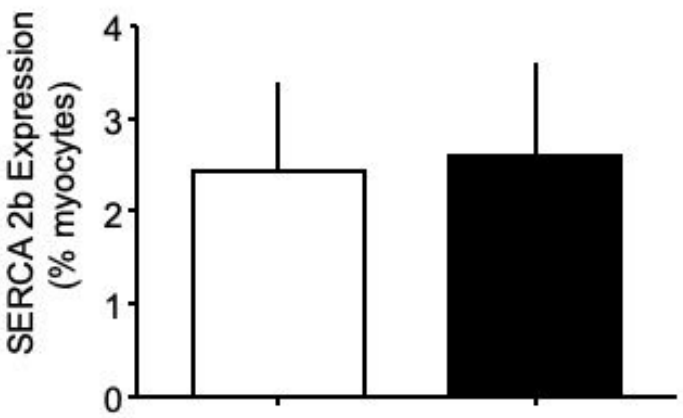

B)

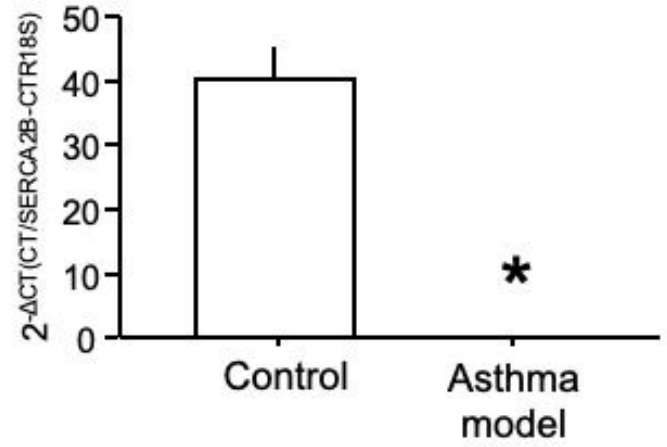

C)

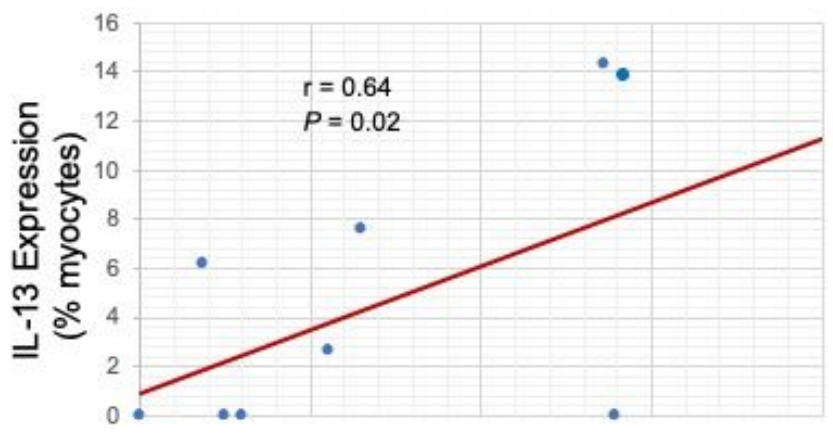

D)

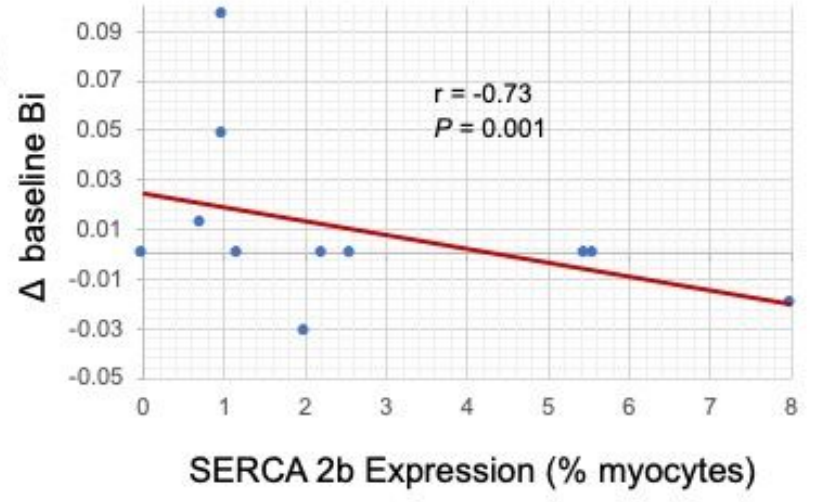


SERCA2b expression in asthma model guinea pigs. (A) Number of isolated airway myocytes that expressed SERCA2b determined by flow cytometry. (B) SERCA2B gene expression measured by RT-PCR. Scatter graphs showing that the number of myocytes that expressed SERCA2b was correlated (C) directly with the number of myocytes that expressed IL-13 and (D) inversely with the changes ( $\square$ ) in the baseline broncho-obstructive index $(\mathrm{Bi}) .{ }^{*} \mathrm{P}=0.00001$ compared with the control (unpaired Student's t-test). $\mathrm{r}=$ Spearman correlation coefficient; $\mathrm{P}$ = paired Student's t-test.

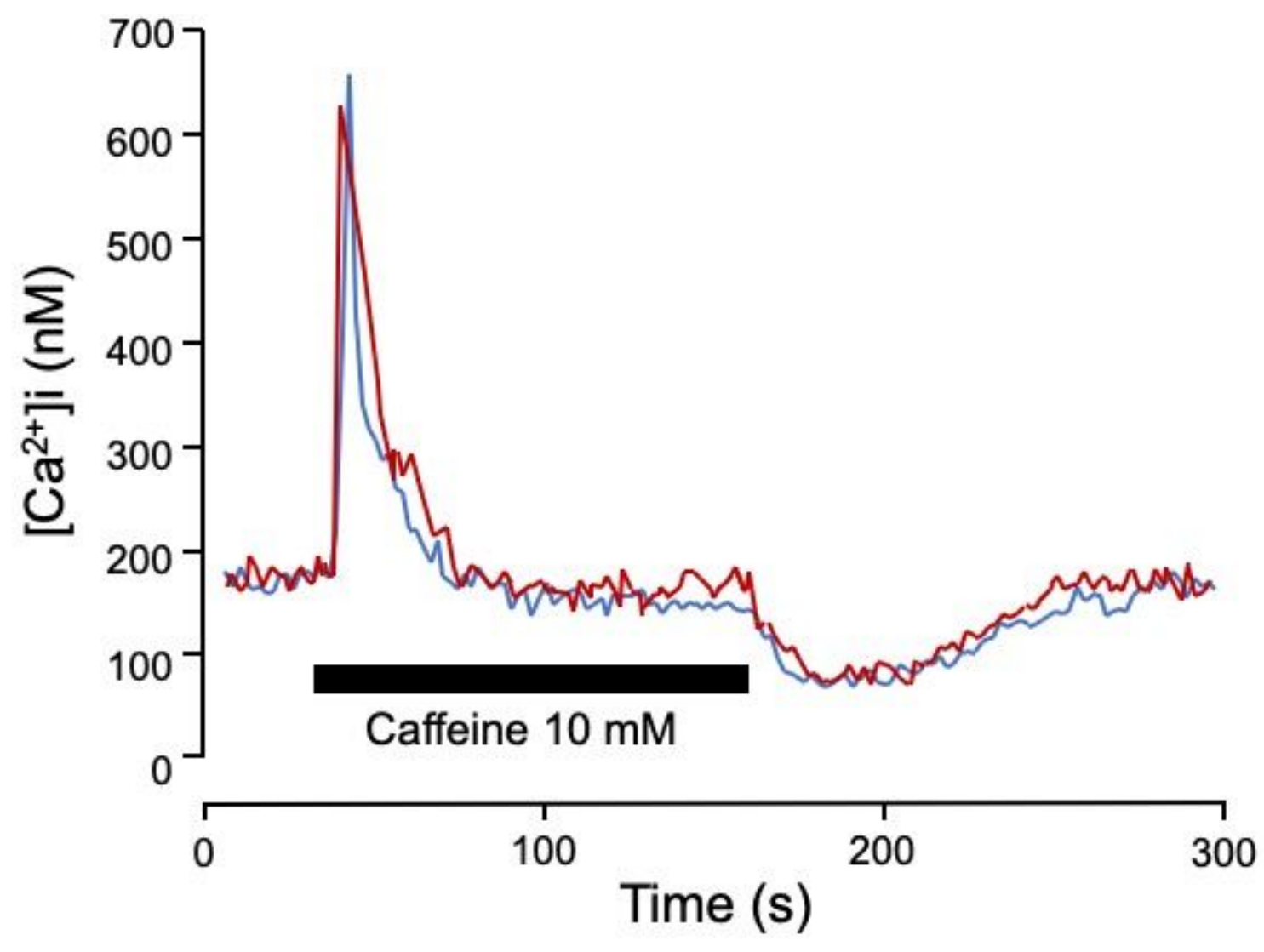

\section{Figure 7}

Representative recording showing the changes in intracellular Ca2+ levels ([Ca2+]i) induced by caffeine $(10 \mathrm{mM})$ in myocytes isolated from control (red) and asthma model guinea pigs (blue). The withdrawal of caffeine induced a Ca2+ undershoot. 